Original Article

\title{
A Delphi Approach to Developing a Core Competency Framework for Registered Nurses in Karnataka, India
}

\author{
Hemalatha R. ${ }^{1}$, B.S. Shakuntala ${ }^{2}$ \\ ${ }^{1}$ Principal, Universal College of Nursing Bangalore, ${ }^{2}$ formerly Dean, AECS M aaruti College of Nursing. \\ Corresponding Author : Hemalatha R., Principal, Universal College of Nursing, Bannerghatta Road, Bangalore-560 076. \\ Mobile: +919448721208 E-mail: hemamach@gmail.com
}

$\begin{array}{ll}\text { Received } & : 05.01 .2018 \\ \text { Review Completed } & : 13.05 .2018 \\ \text { Accepted } & : 14.05 .2018\end{array}$

Keywords : Core Competency framework, Delphi approach, entry level competencies, nursing students, core competencies

\begin{tabular}{|c|}
\hline Access this article online \\
\hline Quick Response Code \\
\hline
\end{tabular}

\begin{abstract}
:
This paper describes the results of a modified Delphi approach to gain consensus on a core competency framework for entry level nursing graduates in Karnataka. Based on extensive review of literature, A series of semi structured questionnaires were mailed to fifteen experts from nursing education and Practice and after refining and validating the competency statements consensus in core competency framework emerged consisting of nine distinct Domains - Valuing Human Beings, Professional Nursing Practice, Communication and Interpersonal Relationship, Professional, Legal and Ethical framework, Knowledge and application of knowledge, collaborative therapeutic Practice, Research Utilization , M anagement of Nursing Services, Professional Advancement with accompanying competency elements and Performance Criteria. . This core competency framework based on the Indian Nursing Council's Standards of Nursing Practice was developed as a benchmark to outline the minimum entry level competencies for new nursing graduates. This study finds potential value in standardising the Competencies to be acquired for nursing graduates and also setting the path forward for a Competency Based Assessment.
\end{abstract}

\section{Introduction}

The design of pre-registration education programs and the evaluation of their success are based on the regulations and standards set by Indian Nursing Council. A comprehensive program provides the basis for preparation of nurses. This is designed to ensure that nurses, who successfully complete undergraduate programs, are safe to practice.

Competency is normally assumed to be the end point of pre-registration education, with new graduates possessing the necessary knowledge and cognitive and psychomotor skills to be safe and effective to practice at a beginning level in the health care environment. ${ }^{1}$ Competence at a beginning level is taken to mean entry-level competence for professional practice.

Core competencies are the essential competencies that a registered nurse is expected to possess at entry to practice on completion of their nursing education in order to provide the public with safe, ethical and quality care.

Core nursing competencies are reported as important for adapting to new environments and for performing effective professional care. Recent research indicates that nurses' satisfaction with their own nursing competencies is a key predictor to overall satisfaction with job performance. The naming of competencies is reported as clarifying the practice knowledge of clinicians and provides a language for articulation and expansion of nursing practice. $^{2}$

Currently, there is a debate as to whether these regulations and standards adequately prepare the new graduates to be fit and competent to practice at the point of registration. There is a need to review pre-registration programs so that they enable and empower the nurse graduates. 
While different contexts of practice and roles will require competencies specific to the client population and the practice settings, a set of core competencies is integral to nursing practice. These competencies build on the registered nurses education and experience in the areas of clinical expertise, research and professional leadership.

Establishing and maintaining competency standards of practice is a major function of any professional organization and clearly reflects the specific functions and activities that the nurses provide, as opposed to the functions of other health care workers.

Therefore, identifying a cluster of core competencies exclusively for the nursing profession and ensuring that these competencies are developed among its professionals will help in maintaining the standards of the profession and ensures consistency and uniformity in the professional practice. $^{3}$

The Australian Nursing Council has outlined several reasons for the development of competency standards in Nursing. These included 1) expressing the scope of nursing 2 ) reducing diversity and facilitating nursing registration throughout Australia 3) enhance professionalism 4) increase congruence between professional education and workplace skills 5) guide educational programs 6) provide career structures. ${ }^{4}$

The underlying premise of this research is that if educators did not know or were unable to interpret the competency standards expected of nurses in India which formed the foundation of their practice, on what basis were they making professional judgments about competence? The study aimed to draw together a group of experienced nursing professionals to identify and obtain consensus on core competencies essential for entry level registered nurses. These competencies will be useful to the nursing education and practice sectors to prepare and assess graduating nurses' fitness to practice.

\section{Materialsand Methods}

The Delphi technique provides a quantitative means of assessing the judgment of experts. It consists of a series of intensive questionnaire rounds among a panel of experts interspersed with controlled opinion and feedback. Each round of a Delphi technique involves a response-analysisresponse-feedback process. ${ }^{5}$ This technique was modified from the traditional Delphi technique by using mostly structured with an option to give their comments for each item. The Delphi approach was conducted in 2 phases.

\section{Phase I}

Literature review: A literature review to develop Core competency framework was undertaken in the areas of competencies, practice standards, competency standards in Nursing. Analysis of the literature was done and the common competencies or standards were short listed. The Core Competency framework was based on the Indian Nursing Council Standards of Nursing Practice. ${ }^{6}$

\section{Phase II}

The phase II was conducted in 3 rounds in which the experts were given the propositions about the competencies and they were asked to rate them as essential, marginal and not relevant. At the end of each round, the result of the previous round was embedded and the process was repeated until consensus was attained.

The phase ll consisted of the followingsteps:

1. Panel Selection : Potential participants for this study were identified through their expertise in the field of nursing education or in nursing Practice such as Nursing Principals, Senior Nurse Educators, Nursing Administrators of hospitals and patient care units. Data collection occurred over a three month period from October 2008 to January 2009. A total of fifteen (15) experts completed the three rounds of survey.

2. Round I : An initial draft competency document was framed using existing competency documents and INC Standards of nursing Practice as a resource. At round 1 , the experts were asked to identify the competency domains essential for nursing graduates. They rated the competency domains on a three point rating scale (from Essential to not relevant) and rank them in the order of importance. They were provided opportunities for 
comments, suggestions or modifications related to each competency domains. Panelists were asked to comment on the necessary knowledge and skills, as well as the necessary attitudes, values, beliefs, and behaviors. Prior to the commencement of the Delphi rounds, the criterion for consensus was set as an agreement rate of 80 percent and above.

3. Round II and Round III: Responses to the first round were collated and used to construct a revised document. The panelists' comments were reviewed and competency elements and performance criteria for each competency domain was added to the revised document and sent to the 15 experts who completed Round I. The rating scales remained the same i.e., Essential to Not relevant. The results from Round 2 allowed the expert panel to 'tighten up' the document and minimize duplication or the inclusion of unnecessary information. At Round III, Experts were asked whether they agreed with results of Round II.

\section{Results}

Of the 15 experts who agreed to participate in the Delphi study, 8 were in the Academic and 7 in the Practice area. In Round I, 9 categories of core competency domains were deemed acceptable as they had 80 percent or more than 80 percent consensus. The domains were Valuing Human Beings, Professional Nursing Practice, Communication and Interpersonal Relationship, Professional, Legal and Ethical framework, Knowledge and application of knowledge, collaborative therapeutic Practice, Management of Nursing Services, Research Utilization and Professional Advancement. The domain of 'Management of Nursing Services' had consensus of 70 percent. Therefore, the experts who did not find it relevant alone were sent the feedback with the results. During the feedback, 80 percent consensus was there, therefore, the item was retained.

Table 1 : Core Competency Domains and the ordering of the Domains after Round 1

\begin{tabular}{|l|c|c|c|c|}
\hline Core Competency & Source & $\begin{array}{c}\text { Initial } \\
\text { ordering }\end{array}$ & $\begin{array}{c}\text { Ordering } \\
\text { after Rd I }\end{array}$ & Agreement \\
\hline Valuing Human Beings & INC & 4 & 1 & $12 / 15$ \\
\hline Professional Nursing Practice & INC & 1 & 2 & $15 / 15$ \\
\hline Communication and Interpersonal Relationship & INC & 3 & 3 & $15 / 15$ \\
\hline Professional, Legal and Ethical Framework & INC & 2 & 4 & $12 / 15$ \\
\hline Knowledge and Application Of Knowledge & CNO & 7 & 5 & $12 / 15$ \\
\hline Collaborative Therapeutic Practice & Panel & 8 & 6 & $13 / 15$ \\
\hline Management of Nursing Services & INC & 5 & 7 & $13 / 15$ \\
\hline Research Utilization & Panel & 9 & 8 & $14 / 15$ \\
\hline Professional Advancement & INC & 6 & 9 & $12 / 15$ \\
\hline
\end{tabular}

Table 1 shows the initial ordering followed based on the INC Standards of Nursing Practice. After Round I, 80 percent of the experts ranked the core competency of 'Valuing Human Beings' on the top. Research Utilization and Professional Advancement were placed at the bottom of the table.

Table 2 : Competency domains and competency elements after Round II

\begin{tabular}{|l|c|c|}
\hline Core Competency Framework & Source & Consensus \\
\hline Valuing Human Beings & & \\
Enhances the dignity, individuality and self esteem & INC & $86.6 \%$ \\
\hline Actively maintains rights of all individuals and in particular the vulnerable groups. & INC & $80 \%$ \\
\hline $\begin{array}{l}\text { Professional Nursing Practice } \\
\text { Provides comprehensive, safe and effective evidence-based nursing care to achieve identified } \\
\text { individual/group health outcomes reflecting nursing process approach }\end{array}$ & INC/ & $100 \%$ \\
\hline Care is provided in a safe environment & ANMC \\
\hline Collaboration with individual, groups and community in promoting health \& preventing illness & Panel & $86.6 \%$ \\
\hline $\begin{array}{l}\text { Communication \& Interpersonal Relationship } \\
\text { Fosters interpersonal relationship with individuals and families }\end{array}$ & INC & $93.3 \%$ \\
\hline Care includes strategies to promote learning of individuals, groups & INC & $93.3 \%$ \\
\hline Expression of effective communication & Panel & $86.6 \%$ \\
\hline
\end{tabular}




\begin{tabular}{|l|c|c|}
\hline Core Competency Framework & Source & Consensus \\
\hline $\begin{array}{l}\text { Professional, Legal \& Ethical Framework } \\
\text { Care is provided within a legal framework. }\end{array}$ & INC & $100 \%$ \\
\hline Care is documented and reported accurately and completely & INC & $100 \%$ \\
\hline Shows awareness of, and sensitivity to values and mores of clients in ethical decision making & WPSEAR & $86.6 \%$ \\
\hline $\begin{array}{l}\text { Knowledge \& Application of Knowledge } \\
\text { Acquires knowledge relevant to the professional nursing practice }\end{array}$ & WPSEAR & $86.6 \%$ \\
\hline Care reflects the application of theoretical knowledge in professional nursing practice & Panel & $86.6 \%$ \\
\hline $\begin{array}{l}\text { Collaborative Therapeutic Practice } \\
\text { Care ensures effective M ulti-disciplinary teamwork }\end{array}$ & Panel & $80 \%$ \\
\hline $\begin{array}{l}\text { Management of Nursing Services } \\
\text { It reflects use of effective techniques }\end{array}$ & INC & $80 \%$ \\
\hline It includes organizing the workload to facilitate client care. & ICN & $80 \%$ \\
\hline Organizes and utilizes resources efficiently & INC & $80 \%$ \\
\hline Awareness of disaster preparedness and disaster management & INC & $75 \%$ \\
\hline $\begin{array}{l}\text { Research Utilization } \\
\text { Nursing care reflects the commitment to use research information effectively and appropriately. }\end{array}$ & Panel & $80 \%$ \\
\hline $\begin{array}{l}\text { Professional Advancement } \\
\text { Nursing care activities which focus on the advancement of profession }\end{array}$ & INC & $80 \%$ \\
\hline
\end{tabular}

INC: Indian Nursing Council ${ }^{6}$; ANM C: Australian Nursing and Midwifery Council ${ }^{4}$; WPSEAR: Western Pacific South East Asian Region, ${ }^{7}$ ICN: International Council for Nurses, ${ }^{8}$ CNO: College of Nurses of Ontario ${ }^{9}$

The results of the Round II indicated that most of the items had $80 \%$ consensus. Item 'Disaster Preparedness' in the Management of Nursing Services had 70 percent agreement. Only that item was sent for Round III to the members who did not consider it relevant. As it still had $75 \%$ consensus, the item was removed from the competency list. However, the item was included in the performance criteria and not as a competency element. Items such as Nurse as Change Agent, Nurse as Manager were recommended by experts in Round II. As Nurse as Change agent had only 50 percent agreement it was not included. Nurse as manager was already included as a Domain in ' $M$ anagement of Nursing Services', hence it was dropped by experts in Round III. The final draft of the Core Competency framework comprised of 9 competency domains and 19 competency elements with description of performance behaviors. All the performance behaviors relevant to the particular competency element were included. However, the list of performance behaviours is not exhaustive.

\section{Discussion}

The Core competency framework in the present study based on the Indian Nursing Council Standards of Nursing Practice consisted of 9 competency domains and 19 competency elements with descriptions of expected performance behaviors. The Core Competency framework in this study is based on Indian Nursing Council Practice Standards 6 practice areas that included Professional accountability, Nursing Practice, Communication and Interpersonal relationship, Valuing Human beings, Management and Professional advancement. ${ }^{3}$ In addition to these, the present study included areas such as knowledge and application of knowledge, Research utilization consistent to the competencies developed by licensing bodies in Australia, European Union ${ }^{11}$ and Canada. The competencies developed in the present study are also consistent to the competencies identified in ICN framework; Professional ethical legal practice, Care provision and Management, Professional development. ${ }^{8}$

However, a study conducted in Taiwan has used a different set of dimensions to competency - basic care competency, community health management competency, teaching competency and self- development competency. ${ }^{2}$

This study has developed Core competencies to be demonstrated in all areas of nursing practice irrespective of the specific context and setting. However, Benner, Tanner and Chesla determined that the degree of competence in 
nursing practice is experience based and context specific and that nurses competent in one setting may be incompetent in another. ${ }^{10}$

Several areas within the competencies may require further discussion, debate, and refinement. For instance, competencies related to the professional practice could be elaborated. Competencies related to disaster management did not have consensus, yet every nursing graduate needs to be equipped with skills and abilities towards disaster preparedness and management.

The size and composition of the expert panel may limit the generalizability of the study. A panel size of fifteen fits within the Delphi guidelines as reliability is shown to be maximized with a panel size of $12,{ }^{5}$ though it remains unclear if a larger sample size and a panel of nursing experts from different parts of country would have altered the level of agreements on the competency domains.

\section{Conclusion}

This study developed the Core competency framework for the entry level registered nurses using a M odified Delphi technique and identified 9 competency domains in the areas of Valuing Human Beings, Professional Nursing

\section{References}

1. Nursing Council of New Zealand. Competencies for Registered Nurses. Dec 2007. P 32 www.nursingcouncil.org.nzAccessed June 2009

2. Tzeng HM Nurses' self assessment of their nursing competencies, job demands and job performance in the Taiwan hospital system. International Journal of Nursing Studies. 2004; 4(5): 487-96

3. Wells $\mathrm{E}$. ANCl Competencies: An Investigation of uniqueness and importance. PhD thesis, Griffith University: 2002 Sep ; P 32-4

4. Nursing and midwifery Board of Australia. National Competency Standards for the Registered nurse. Available from www.nursingmidwiferyboard. gov.au (last accessed 2011 June 10)

5. Hughes R. Competencies for effective public health nutrition practice: A developing consensus. Public Health Nutrition. 2004; 7(5): 683-91

6. Practice Standards for Nurses in India. Teaching M aterial for Quality Assurance M odel: Nursing. Indian Nursing Council, New Delhi.2006
Practice, Communication and Interpersonal Relationship, Professional, Legal and Ethical framework, Knowledge and application of knowledge, collaborative therapeutic Practice, Research Utilization, Management of Nursing Services, Professional Advancement with accompanying competency elements and Performance Criteria.

Development of the generic competencies in this study will facilitate the development of competency in different specialty areas. This competency framework will provide regulatory bodies with a preliminary draft to work on a large scale and keeping national interests in mind to help in the credentialing / licensing procedure. This will allow the regulatory bodies to explore the assessment process for the 'fitness of practice' of new graduates.

\section{Acknowledgment}

The author wishes to acknowledge the experts who participated in the 3 rounds of Delphi Survey- Prof Abanti Gopan, Prof Ambika Ravindran, Dr Jeyaseelan A Devadasan, Dr Padmaja A, Dr C Susila, Dr Bibiana Vijay, Dr J Rukumani, Dr J Jasmine, M rs Shiny Jacques, M rs Rosline, M rs C Vasanta, M rs Santhi Tamilmani, Ms Kamalaveni, Dr M ala, Lt Col Binu Sharma.

7. Common Competencies for Registered Nurses. WPSEAR: ANMC Australia; M arch 2006

8. International Council of Nurses. Nursing Continuum Framework and Competencies. Consultation draft. Jul 2007.

9. Entry to Practice Competencies For Ontario Registered Nurses as of January 1, 2005.College of Nurses of Ontario. Pub. No. 41037; 2004

10. Cowan DT, Wilson-Barnett DJ, Norman IJ, Murrells T. Measuring Nursing Competencies: Development of self assessment tools for general nurses across Europe. International Journal of Nursing studies. 2008; 45: p 902-13

11. Benner, P., Tanner, C. A., \& Chesla, C. A.. Expertise in nursing practice: Caring, clinical judgment, and ethics . 2nd ed.. 2009. New York, NY: Springer. 